\title{
ВЗАИМОСВЯЗЬ МОТИВАЦИИ И ПРОФЕССИОНАЛЬНОЙ НАПРАВЛЕННОСТИ ЛИЧНОСТИ КУРСАНТОВ ВОЕННЫХ ИНСТИТУТОВ ВОЙСК НАЦИОНАЛЬНОЙ ГВАРДИИ РОССИЙСКОЙ ФЕДЕРАЦИИ
}

\section{RELATIONSHIP OF MOTIVATION AND PROFESSIONAL ORIENTATION OF THE PERSONALITY OF CADETS OF MILITARY INSTITUTES OF THE NATIONAL GUARD OF THE RUSSIAN FEDERATION}

\section{R. Fakhurdinov}

Summary: This article examines modern psychological approaches to the study of motivation and professional orientation. The essence of the personality orientation and the methodological basis of its formation are revealed by the psychological factors that determine the motives of the cadets' activities. The results of the study of the characteristics of the orientation of the cadets' personality are presented.

Keywords: motivation, focus, professional focus.
A ктуальность исследования. В условиях современности при формировании войск национальной гвардии РФ целесообразно говорить о новом перечне требований, которые предъявляются к формированию военно-профессиональной направленности обучающихся образовательных учреждений войск национальной гвардии нашего государства.

Необходимые профессиональные аспекты личности курсанта развиваются, главным образом, благодаря его активному участию в образовательных процессах учебного заведения и профессиональной деятельности. В основе личностного становления лежит формирование профессиональной направленности, профессионального самосознания, приобретение соответственного профессии багажа знаний, умений и навыков [8].

Рассматривая понятие профессиональной направленности, подразумевают такую интегративную характеристику личности, как психологическая готовность к трудовой деятельности. От этой важнейшей характеристики напрямую зависят карьерные перспективы, динамика в профессиональной среде, степень удовлетворённости работой и её результатами, заинтересованность в профессиональном развитии.
Фахурдинов Ренат Равильевич

Новосибирский ордена Жукова военный институт имени генерала армии И.К. Яковлева войск национальной гвардии Российской Федерации, г. Новосибирск yul-zhivaeva@yandex.ru

Аннотация: В настоящей статье рассматриваются современные психологические подходы к исследованию мотивации и профессиональной направленности. Раскрывается сущность направленности личности и методологические основы ее формирования у курсантов военных институтов войск национальной гвардии Российской Федерации. Выделены психологические факторы, определяющие мотивы деятельности курсантов. Приведены результаты изучения особенностей направленности личности курсантов.

Ключевые слова: мотивация, направленность, профессиональная направленность.

Профессиональная направленность является одной из наиболее значимых личностных характеристик будущего военнослужащего. Ей определяются специфические особенности мотивационной составляющей обучающегося, отвечающей за применение знаний и навыков в выбранной им сфере деятельности [2]. Говоря о профессиональной направленности курсантов, стоит понимать, что она является крайне сложной и разносторонней системой, состоящей из множества взаимосвязанных элементов [4]. Согласно деятелю отечественной психологической науки Н.С. Пряжникову, можно обозначить пять базовых уровней, которые включает в себя формирование профессиональной направленности студентов ВУЗов, а именно:

- подготовительный этап, обязательный перед профессиональным самоопределением обучающегося;

- осуществление выбора конкретной профессии или профессиональной деятельности;

- освоение выбранной специальности;

- углубление и расширение совокупности знаний, умений и навыков, которые обучающийся получает самостоятельно в процессе работы, самосовершенствование в избранной области;

- изучение новых или смежных специализаций [11]. 
Российская психологическая наука отводит весомую роль мотивации обучающегося. Мотивация выступает ключевым фактором, оказывающим существенное влияние не только на качество и результативность профессиональной деятельности индивида, но и на степень его удовлетворённости собственной работой [10].

Одна из наиболее значимых и сложных проблем в психологической науке - это проблема мотивов и мотивации человеческого поведения. Однако, как бы ни была велика её важность, выдающийся отечественный психолог А.Н. Леонтьев однажды высказался о проблеме мотивации и поведенческих мотивов достаточно категорично, охарактеризовав её как «мешок, куда ссыпали самые разные понятия» [6].

Высказывание А.Н. Леонтьева не лишено оснований, так как множество учёных не смогли прийти к консенсусу в чётком определении психологических феноменов, выступающих в роли мотивов. Так, Л.И. Божович понимал под мотивами намерения, представления, идеи, чувства, переживания; Х. Хекхаузен относил в эту категорию потребности, влечения, побуждения и склонности личности; Г.А. Ковалёв отводил ключевую роль морально-этическим, политическим, социальным установкам и намерениям индивида; К.К. Платонов определял мотивы как специфические состояния психики и личностные особенности; сам А.Н. Леонтьев склонялся к мнению о том, что под мотивами стоит рассматривать предметы внешнего мира; А. Маслоу называл мотивами установки. Такое разнообразие взглядов на феномен представляется вполне оправданным, стоит лишь вспомнить о том, что само человеческое поведение по природе своей является крайне многообразным.

От мотивационной сферы напрямую зависит, какую степень трудолюбия и настойчивости продемонстрирует человек, занимаясь избранной им деятельностью и стремясь достичь её результатов. Мотивация представляет собой «особый психический процесс или особое психическое действие со своим строением и с функцией формировать побуждение» [1].

Для западной психологической науки характерен подход, изучающий мотивацию в качестве определённой личностной характеристики, от которой зависит устойчивость сформированного индивидом отношения к осуществляемой им работе. Так, изучению этого вопроса посвятили труды Г. Мюррей, Г. Олпорт, Д. Макклелланд.

Описывая факторы, которыми определяются мотивы человека, необходимо учитывать значимость психических регуляторных контуров, то есть в определённой мере самостоятельных образований, обладающих сравнительной устойчивостью, за счёт которых осуществля- ется согласование всей мотивационной сферы [3].

По признаку ценностных ориентаций человека мотивы можно условно разделить на две категории: социально важные и важные личностно, индивидуально. В контексте этих двух групп становится ярко выражено влияние типа профессиональной направленности индивида на его мотивационную сферу.

Ввиду вышесказанного, целесообразным будет перечислить основные психоэмоциональные факторы, непосредственно влияющие на систему мотивации человека.

1. Ценностный: отвечает за образование системы ценностей, присущей избранной индивидом профессиональной деятельности, актуализирует имеющиеся мотивы.

2. Социальный: посредством него достигается ориентировка индивида на социальную среду, в которой он находится и осуществляет свою профессиональную деятельность.

3. Саморегуляция: индивид оказывает непосредственное влияние на свои мотивы, осознанно и целенаправленно контролируя собственную деятельность, применяя для этого существенные усилия воли. Обеспечение саморегуляции не представляется возможным, если человек не проявляет самостоятельности и не готов брать на себя ответственность за свои действия.

4. Эмоциональный: способствует эмоциональной поддержке деятельности, которая оказывает влияние на уровень и направленность активности, а также на формирование у человека необходимого отношения к осуществляемым им действиям.

5. Информационный: базируется на знаниях, которые человек приобретает в процессе обучения. Большинство психологов согласны с выделением, прежде всего двух типов мотивации: внешней и внутренней, которые строятся на системе допущений о природе человека и устанавливают законы индикации (намерения к выполнению мотивационного действия) и регуляции поведения.

Для многих учёных характерно деление мотивационной системы на такие категории, как внешняя и внутренняя. Данная классификация не является абсолютной и базируется на комплексе допущений, свойственных человеческой природе.

В трудах зарубежных авторов описываются две разновидности мотивации, отличающиеся друг от друга рядом специфических особенностей: экстринсивная мотивация (сформированная под влиянием внешних факторов) и интринсивная (сформированная посредством индивидуально-личностных потребностей, намерений, помыслов и интересов человека). При этом только для второго типа мотивации характерно осуществление 
индивидом деятельности по собственной воле. Х. Хекхаузену принадлежит авторство книги, в которой он систематизирует перечень публикаций, исследующих вышеупомянутую проблематику [12].

Многие авторы выделяют и другие специфические типы мотивации, например «мотивацию благополучия», профессиональные мотивы, мотивы самоутверждения; утилитарные мотивы; понимаемые, осознаваемые и реально-действующие мотивы; актуальные и потенциальные мотивы и др. При этом стоит признать, что научные труды этих деятелей не наделяют проблематику мотивационной сферы индивида, его профессиональной и личностной направленности исчерпывающей изученностью. Имеющиеся публикации, напротив, указывают на степень непроработанности данной области знания и формируют перечень направлений, в которых необходимо изучать специфику направленности и мотивации человеческой личности в наши дни.

В программе образовательных учреждений, осуществляющих профессиональную подготовку военнослужащих, отводится важная роль такому аспекту обучения, как развитие у курсантов профессиональной мотивации. Сюда можно отнести развитие и укрепление заинтересованности обучающегося в особенностях выбранной им специальности; формирование определённых взглядов, необходимого отношения к профессиональной деятельности; воспитание в курсантах готовности действовать в любой ситуации, руководствуясь правомерными и деловыми аспектами; развитие у будущих военнослужащих потребности и желания учитывать перспективы профессиональной деятельности и соотносить с ними личные цели.

Большое значение, особенно в процессе профессиональной подготовки будущих офицеров, придаётся формированию профессиональных мотивов:

- формирование интереса к специфике профессиональной деятельности;

- отношение к службе и избранной специальности;

- потребность всегда поступать исходя из правомерных и деловых целей;

- стремление исходить из перспектив службы и связывать с ними личные планы;

- здоровые служебные притязания, стремление к самовыражению и самоутверждению и др.

Понятие «направленности» является одним из корневых вопросов, изучаемых психологией и педагогикой. Определения, которые дают авторы данному термину, могут иметь некоторые отличия и расхождения, однако большинство учёных уделяют особое внимание мотивационной сфере индивида.

Стоит кратко упомянуть взгляды А.Г. Асмолова. По его представлению, направленность является ёмким описательным свойством личности индивида. Для того, чтобы исследовать это свойство в полной мере, необходимо отказаться от анализа личностной структуры по элементам и обратиться к принципу анализа по единицам, сформировав перечень требований к единицам анализа структуры личности.

А.Г. Асмолов предлагает следующий список требований: наполненность предметным содержанием; динамичность и раскрытие происхождения, содержания детерминации формирования структуры личности; объяснение развития и саморазвития личности; свойства целого, содержащиеся в единице в виде противоположностей; операционализируемость и др. [5].

По мнению Б.Ф. Ломова, направленность выступает ведущей личностной характеристикой. Учёный считает, что направленность является системообразующим фактором, оказывающим непосредственное влияние на развитие общего психологического профиля индивида.

Согласно взглядам Р.С. Немова и Л.И. Божович, направленность есть ничто иное, как комплекс устойчиво преобладающих мотивов, формирующих целостную структуру личности человека [7].

Особую значимость среди составляющих направленности имеют интересы человека, складывающиеся на базе его потребностей. Потребности выступают фундаментальными свойствами личности, обозначают её нужду в каких-либо ресурсах и представляют собой неисчерпаемый источник активности и психической энергии.

Чтобы определить особенности направленности индивида, мы провели исследование, используя методику диагностики направленности личности, которая даёт возможность узнать: каковы истинные глубинные устремления человека, что он выделяет для себя как наиболее значимое и ценное Методика диагностики направленности личности Б. Басса (Опросник Смекала Кучера)

База и выборка исследования. В исследовании приняли участие 110 курсантов 5 курса 110 курсантов 3 курса Новосибирского военного ордена Жукова института имени генерала армии И.К. Яковлева войск национальной гвардии Российской Федерации.

Анализируя результаты исследования, мы имеем возможность сделать следующее заключение. Результаты исследования представлены на рисунке 1-2.

В ходе исследования были получены следующие результаты: для 30\% испытуемых характерен высокий 


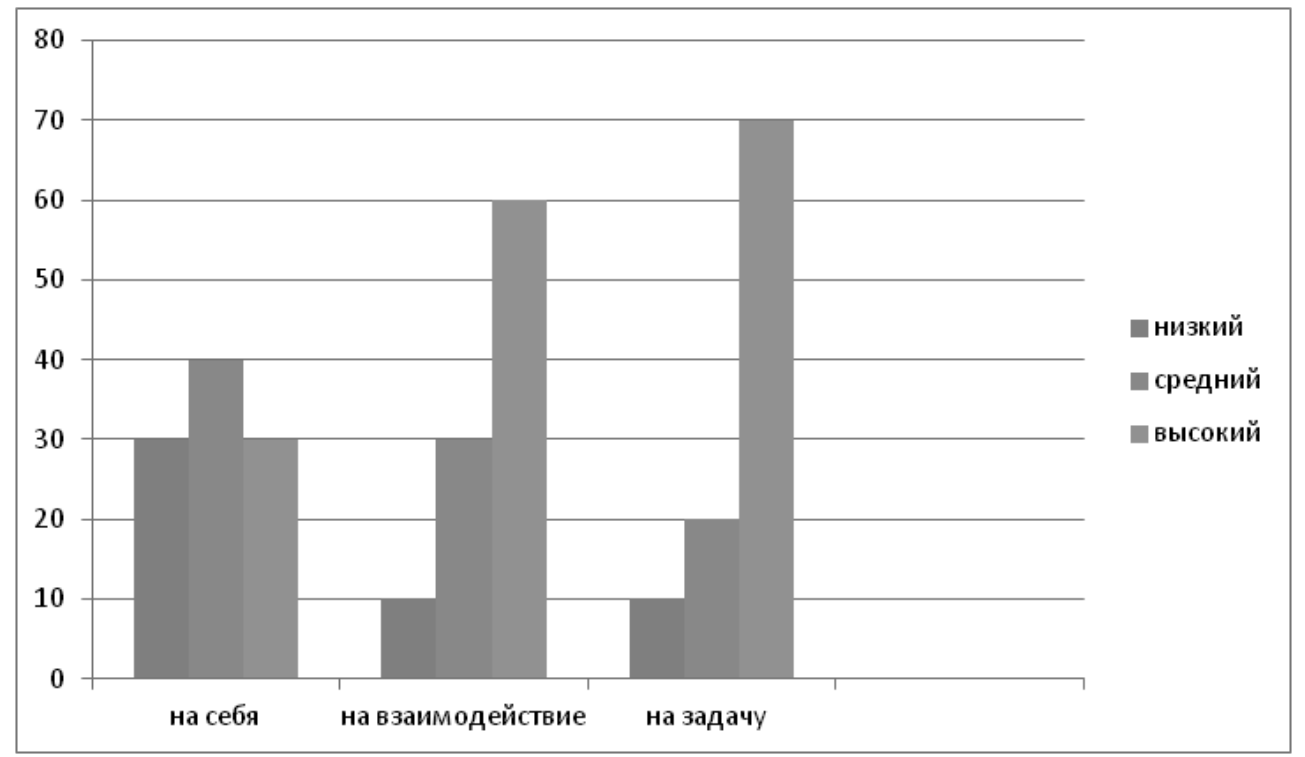

Рис. 1. Результаты изучения направленности личности курсантов 5 курса

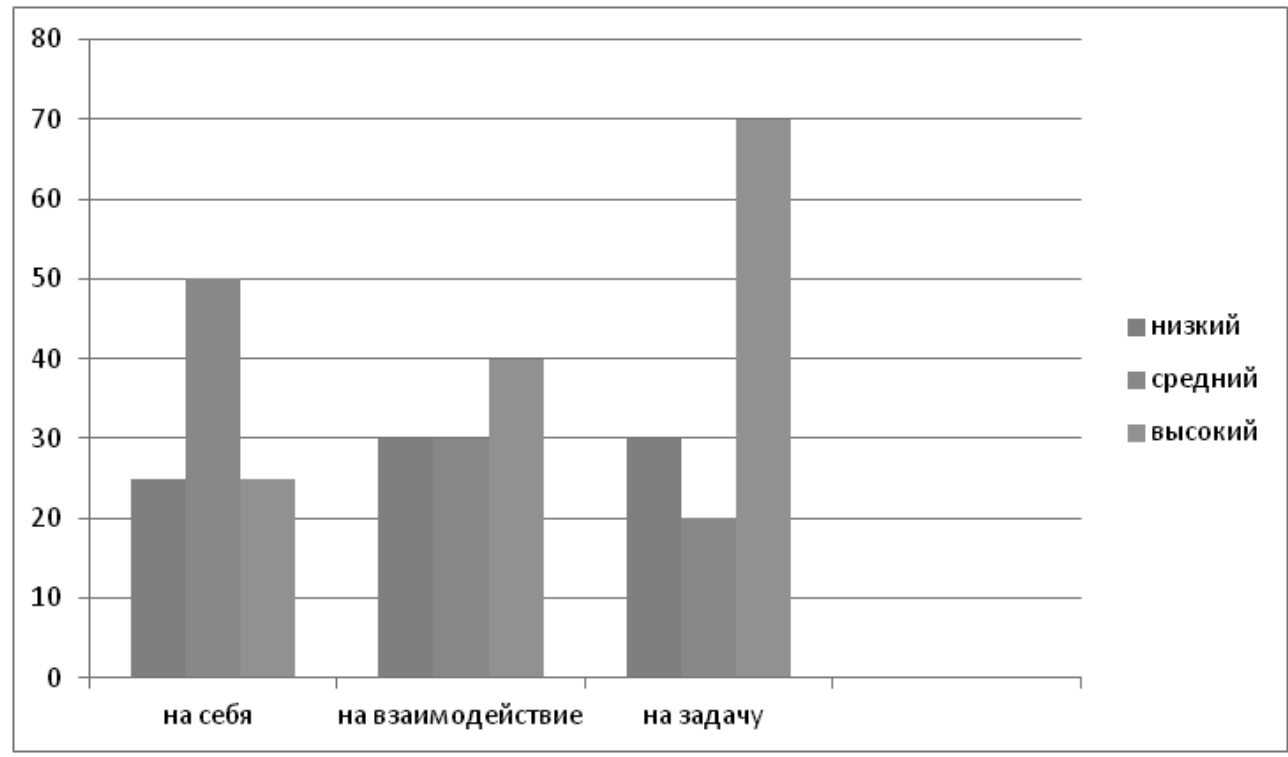

Рис. 2. Результаты изучения направленности личности курсантов 3 курса

уровень направленности на себя, связанной с личным благополучием, стремлением к первенству и престижу. Такие курсанты в большинстве своём обращают внимание только на свои потребности, пренебрегая социальным окружением, а профессиональную деятельность рассматривают, главным образом, как возможность осуществить личные притязания; $40 \%$ респондентов проявили средний уровень направленности на себя. 30\% курсантов обнаружили слабо выраженную направленность на себя. Эти исследуемые осознают, что их окружают товарищи; не нуждаются в одобрении своей деятельности; хорошо чувствуют себя в социальной группе.

Для $60 \%$ опрошенных характерна высокая степень выраженности направленности на взаимодействие: это проявляется в ситуациях, когда поведение человека объясняется необходимостью формирования социальных контактов, желанием установить хорошие отношения с окружением. У $30 \%$ участников направленность на взаимодействие выявлена на среднем уровне.

Этот же показатель слабо выражен у 10\% курсантов. Исследуемые из этой группы не отдают себе отчёта в том, что окружены сверстниками и сотоварищами, не способны установить такую атмосферу в коллективе, которая позволит всем желающим свободно выражать своё мнение.

Только у 10\% курсантов направленность на задачу выражена слабо. Для 20\% исследуемых характерна средняя выраженность этого типа направленности. В высокой степени направленность на задачу свойственна 
$70 \%$ респондентов. Соотнесем показатели исследования курсантов 5 курса с показателями курсантов 3 курса. Результаты исследования представлены на рисунке 2.

Для выявления статистической значимости различий между показателями исследования у курсантов 5 и 3 курсов, мы использовали t-критерий Стьюдента. Полученное значение tэмп.=2,3 по шкале «Направленность на себя » находится в зоне значимости ( $\mathrm{kp} .=1,97$; $\mathrm{p}<0,05)$, что свидетельствует о статистической существенности различий между показателями; по шкале «Направленность на взаимодействие» значение так же находится в зоне значимости tэмп. $=2,6$ (t кр.=1,97; $\mathrm{p}<$ 0,05), что так же свидетельствует о статистической суще- ственности различий между показателями; полученное значение тэмп. $=2,8$ по шкале «Направленность на задачу» находится в зоне значимости ( $\mathrm{t}$ кр. $=1,97 ; \mathrm{p}<0,05$ ), что свидетельствует о статистической существенности различий между показателями. Таким образом, данные статистической обработки свидетельствуют о значимой разнице показателей исследования особенностей направленности личности у студентов 5 и зкурса. Можно отметить, что курсанты старшего курса в большей степени ориентированы на проявление направленности на взаимодействие и на задачу. Полученные нами данные помогли определить, к чему стремятся курсанты, какие приоритеты имеют, что считают наиболее значимым в своей деятельности от курса к курсу.

\section{ЛИТЕРАТУРА}

1. Асеев, В.Л. Мотивация поведения и формирование личности / В.Л. Асеев М.: Мысль, 2006. - С.80 - 93.

2. Божович, Л.И. Проблема формирования личности / Л.И. Божович. --М.: Издательство «Институт практической психологии», 1997. - 352 с.

3. Ильин, Е.П. Мотивация и мотивы/ Е.П. Ильин - СПб.: Издательство «Питер», 2000. - 512с.

4. Климов, Е.А. Психология профессионального самоопределения / Е.А. Климов - М.: Издательский центр «Академия», 2010. - 304 с.

5. Кунц, Л.И. Профессиональная направленность как фактор формирования образа будущей профессиональной деятельности личности: На материалах студентов-психологов: дис. ... канд. псих. наук: 19.00.01/. - Новосибирск., 2005. - 216 с.

6. Лосев, А.Н. Формирование военно-профессиональной направленности будущих офицеров: дис. ...канд. пед. наук: 13.00.08/. - Тамбов, 2004. - 201 с.

7. Малютина, Т.В. Психологические и психофизиологические особенности развития в юношеском (студенческом) возрасте / Т.В. Малютина // Омский нучный вестник. Раздел: Психологические и педагогические науки. - 2014. - № 2 (126). - С. 129 - 132.,

8. Олпорт, Г. Тенденции в теории мотивации // Проективная психология. М., 2010.- С. 55 - 67.

9. Хекхаузен, Х. Психология мотивации достижения / Х. Хекхаузен Пер. с англ. СПб.: Речь, 2011.- 240 с.

10. Шевченко, Т.В. Формирование военно-профессиональной направленности курсантов в процессе воспитательной работы в военном вузе: дис. .... канд. пед. Наук 13.00.08/. - Пенза, 2008. - 171 с. 